\title{
Research on the Phenotypic Characterization of Mrsa Strains Isolated from Animals
}

\author{
IuliaMaria BUCUR*, Viorel HERMAN,Corina PASCU, Ionica IANCU, Janos DEGI and Nicolae CĂTANA
}

Faculty of Veterinary Medicine, Timișoara

*corresponding author: bucur_iulia@ymail.com

Bulletin UASVM Veterinary Medicine 74(1) / 2017,

Print ISSN 1843-5270; Electronic ISSN 1843-5378

DOI:10.15835/buasvmcn-vm: 12610

\begin{abstract}
Currently, at the staphylococci isolated from animals with different diseases, as well as in humans, are monitored the MRSA type strains (Methicillin Resistant Staphylococcus aureus), as the methicillin resistance is associated with the resistance to other antibiotic groups. Methicillin resistance is encoded by mec staphylococcal chromosomal cassettes (SCCmec), which are islands of resistance. The research was made in order to characterize and identify phenotypically the MRSA staphylococci strains isolated from animals.

Researches were made on 240 coagulase positive and coagulase negative strains of staphylococci. Mannitol fermentation was tested on Chapman medium, free coagulase was revealed on Baird-Parker medium and to identify S. aureus subsp. aureus was used the chromogenic medium Chromatic Staph.Methicillin-resistant strains were detected by disc diffusion method, using biodiscs with methicillin, oxacillin and cefoxitin. Also, to identify the MRSA strains, was used the chromogenic medium Chromatic MRSA.

The isolates were positive to mannitol and produced complete haemolysis or were unhaemolytic. A number of 44 strains produced free coagulase on Baird-Parker medium, considered coagulase positive strains, while 196 were coagulase negative strains.The isolates conducted differently to methicillin: $22,08 \%$ of strains were resistant, $51,25 \%$ of strains were susceptible and $26,66 \%$ had intermediate resistance, while $42,91 \%$ of strains wereresistant to oxacillin.The increased frequency of methicillin-resistant strains of staphylococci and, particularly, MRSA strains, determined using the cefoxitin disk diffusion test, which is more reliable than methicillin and oxacillin.On the MRSA chromogenic medium, the methicillin-resistant strains of staphylococci formed colonies with pigment from mauve to orange mauve.

The results obtained by using the disk diffusion test on resistance patterns to 3 beta-lactams, resistant to penicillinase, indicated a different frequency of the resistant strains to these antibiotics. Cefoxitin disk diffusion test revealed a frequency of $2,51 \%$ resistant strains, considered to be MRSA strains.
\end{abstract}

Keywords: chromogen, methicillin, MRSA, resistance, staphylococcus

\section{INTRODCUTION}

Staphylococci strains are considered strains with a highly zoonotic riskthat have a complex epidemiologic circuit, because it can present resistancephenotypes to methicillin

Currently, at the staphylococci isolated from animals with different diseases, as well as in humans, are monitored the MRSA type strains (Methicillin Resistant Staphylococcus aureus),because the methicillin resistance is associated with resistance to other antibiotic groups (Bicheru et al., 2014; Codiță et al., 2008).

Resistance to methicillin is encoded by mec staphylococcal chromosomal cassettes(SCCmec), which are islands of resistance, composed of: $m e c \mathrm{~A}, m e c \mathrm{R} 1$ and mec $\mathrm{O}$ genes, a complex coding the crrA and crrBrecombinases, Tn544transposon and a copy of the plasmid pUB110. Chromosomal 
Tab. 1. Results regarding the antibioresistance testing

\begin{tabular}{ccccccc}
\hline \multirow{2}{*}{ Specification } & \multicolumn{2}{c}{ METHICILLIN } & \multicolumn{2}{c}{ OXACILLIN } & \multicolumn{2}{c}{ CEFOXITIN } \\
\cline { 2 - 7 } & No & $\%$ & No & $\%$ & No & $\%$ \\
\hline CPS susceptible strains & 29 & $65,91 \%$ & 15 & $34,09 \%$ & 43 & $97,73 \%$ \\
\hline CNS susceptible strains & 94 & $47,96 \%$ & 43 & $21,94 \%$ & 180 & $91,84 \%$ \\
\hline TOTAL & $\mathbf{1 2 3}$ & $\mathbf{5 1 , 2 5 \%}$ & $\mathbf{5 8}$ & $\mathbf{2 4 , 1 6 \%}$ & $\mathbf{2 2 3}$ & $\mathbf{9 2 , 9 2 \%}$ \\
\hline CPS intermediate strains & 6 & $13,64 \%$ & 11 & $25 \%$ & 1 & $2,27 \%$ \\
\hline CNS intermediate strains & 58 & $29,59 \%$ & 68 & $28,33 \%$ & 10 & $5,10 \%$ \\
\hline TOTAL & $\mathbf{6 4}$ & $\mathbf{2 6 , 6 7 \%}$ & $\mathbf{7 9}$ & $\mathbf{3 2 , 9 2 \%}$ & $\mathbf{1 1}$ & $\mathbf{4 , 5 8 \%}$ \\
\hline CPS resistant strains & 9 & $20,45 \%$ & 18 & $40,91 \%$ & 0 & $0 \%$ \\
\hline CNS resistant strains & 44 & $22,45 \%$ & 85 & $35,42 \%$ & 6 & $3,06 \%$ \\
\hline TOTAL & $\mathbf{5 3}$ & $\mathbf{2 2 , 0 8 \%}$ & $\mathbf{1 0 3}$ & $\mathbf{4 2 , 9 2 \%}$ & 6 & $2,5 \%$ \\
\hline
\end{tabular}

cassettes can be transmitted, and as a result MRSA type strains are becoming more frequently.These strains can be identified by molecular biology tests and tests that reveal several phenotypic characteristics (Bicheru et al., 2014; Codiță et al., 2008; Pletinckx et al., 2013).

The research was made in order to characterize and identify phenotypically the MRSAstaphylococci strains isolated from animals.

\section{MATERIALS AND METHODS}

The research was made on a total of 240 coagulase positive and coagulase negative strains of staphylococci, isolated from animals. Samples with pathological material were taken with sterile swabs. Inorder to obtain the primary cultures the sowings were made in peptone water and incubated at $37^{\circ} \mathrm{C}$, for $18-20$ hours, under aerobic conditions. Chapman medium was used to obtain pure cultures of staphylococci, which excluded non halotolerant bacteria and highlighted mannitolfermentation.

Free coagulase was revealed on Baird-Parker medium and, for the identification of $S$. aureus subsp. aureus, was used the chromogenic medium Chromatic ${ }^{\mathrm{TM}}$ Staph aureus (Codiță, 2008).

Methicillin-resistant strains were detected by disc diffusion method, using biodiscs with methicillin $(5 \mu \mathrm{g})$, oxacillin $(1 \mu \mathrm{g})$ andcefoxitin (30 $\mu \mathrm{g}$ ). Also, a chromogenic medium (Chromatic ${ }^{\mathrm{TM}}$ MRSA) was used to identify the MRSA strains.

\section{RESULTS AND DISCUSSION}

The results regarding the resistance to these three $\beta$-lactams were different, but however, confirmed that in coagulase positive and negative staphylococci, isolated from animals, theresistance phenotypes to these antibiotics are present.

A number of 44 coagulase positive strains and 196 coagulase negative strains were identified using Baird-Parker medium, strains tested for resistance to these three $\beta$-lactams.

On Chromatic ${ }^{\mathrm{TM}}$ Staph aureus medium used for a rapid discrimination of $S$. aureus subsp. aureus strains, the isolates formed pink-purplishcolonies. Based on this phenotypic character, 47 strains $(19,58 \%)$ were included in this species.

In Table 1 are presented the results from testingthe behavior of coagulase positive and negative staphylococci towards these three $\beta$-lactams.

Coagulase positive staphylococci strains behavior to methicillin, oxacillin and cefoxitin was variable, as follows: $20,45 \%$ of strains were resistant to methicillin, $40,91 \%$ were resistant to oxacillin, while no strain was resistant to cefoxitin. Also, coagulase negative staphylococci strains behavior to methicillin, oxacillin and cefoxitin was different: $22,45 \%$ of strains were resistant to methicillin, $35,42 \%$ were resistant to oxacillin, while only $3,06 \%$ of strains were resistant to cefoxitin.

Coagulase positive and coagulase negative staphylococci strains, had a different behavior to methicillin, an antibiotic frequently used for detection of methicillin-resistance phenomenon. Thus, $22,08 \%$ of the tested strains were resistant to this antibiotic, $51,25 \%$ of the tested strains were susceptible and $29,59 \%$ had an intermediate resistance. 


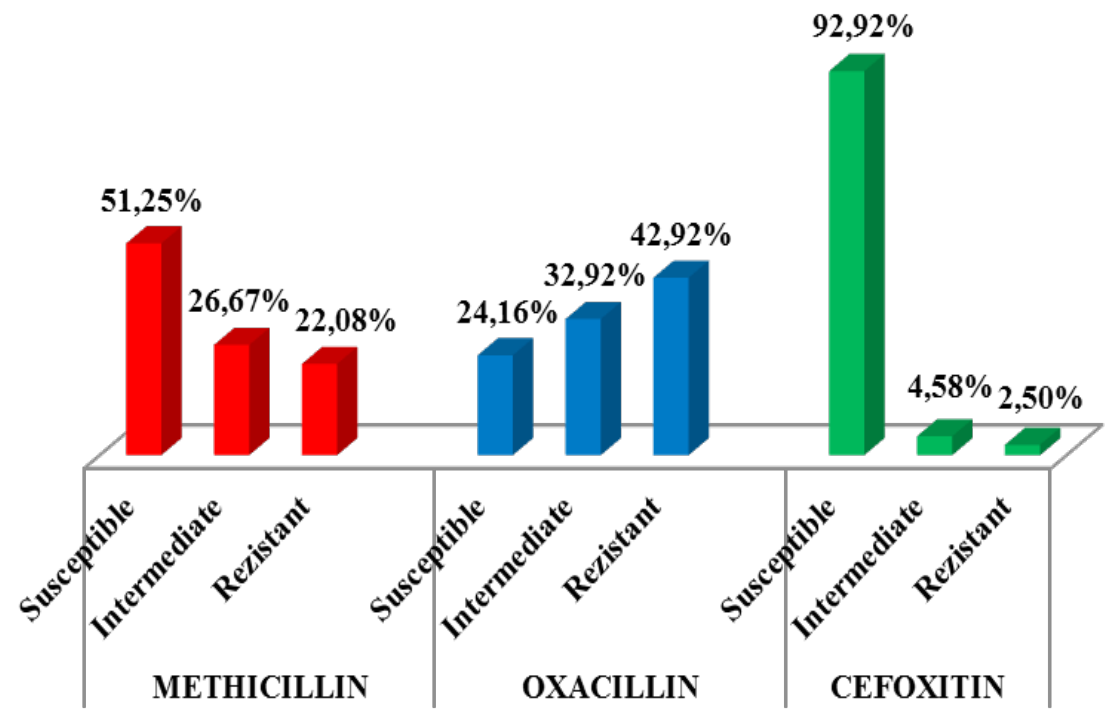

Fig. 1. Resistance phenotypesfrequency of CPS and CNSstrains

In order to detect the cross-resistance of staphylococci to penicillins resistant to penicillinase, oxacillin was recommended, both for its stability and for reproductibility of results. Thereby, the results were as follows: $42,92 \%$ were resistant strains, $21,94 \%$ were susceptible strains and $32,92 \%$ had an intermediate behavior.

The increased frequency of methicillin resistant staphylococci strains, in particular, of S. aureus subsp. aureusstrains, namely MRSA strains, determined the use of disk diffusion test to cefoxitin, an antibiotic more reliable than methicillin and oxacillin. The results obtained on testing the isolates to cefoxitin were: $2,5 \%$ resistant strains, $92,92 \%$ susceptible strains and $4,58 \%$ of strains had an intermediate behavior (Fig. 1.).

On Chromatic ${ }^{\mathrm{TM}}$ MRSA medium staphylococci in this group formed colonies of mauve to orangemauve color.With this culture medium, 39 strains $(16,25 \%)$ were classified as MRSA strains.

Methicillin resistant staphylococci are considered bacteria with zoonotic risk, and the study of animal-human-animal circuit to these bacteria are a major concern for public health. Strains of methicillin resistant staphylococci are frequently isolated, both from farm animals and from pets, but as researches were conducted,the phenomenon of methicillin resistance is particularly aimed at two large groups of staphylococci, respectively coagulase positive and coagulase negative (Boost et al., 2012;
Gordoncillo et al., 2012; Vanderhaeghen et al., 2012; Vanderhaeghen et al., 2013).

Lately, methicillin resistant staphylococci are frequently isolated from swine in intensive growth. These strains have a growing frequency and found in pigs in many countries.

Based on research conducted by numerous collectives, MRSA-ST398 strain was identified, which produce frequent infections in humans (caretakers, farmers, processors and veterinary personnel) and recognized as a highly professional risk strain (Lim et al.,2012).

The importance of MRSA strains to public health and the increasing frequency of these strains require rapid detection methods, both phenotypic and genotypic, like the use of chromogenic media and some variants of the PCR test (Bicheru et al., 2014; Gunderson et al., 2016; Vanderhaeghen et al., 2012; Vanderhaeghen et al., 2013).

Own research confirms the data in the literature regarding the frequency of resistance phenotypes to those three $\beta$-lactams and, in particular, the frequency and zoonotic risk of MRSA strains.

\section{CONCLUSIONS}

A number of 240 strains of staphylococci were isolated and standardized based on the cultural, morphological, tinctorial, hemolytic and mannitol fermentation characters from the samples of pathological material. 
Using the chromogenic media, were discriminated $S$. aureus subsp. aureus strains and the strains belonging to the MRSA group.

The results, obtained by disk diffusion method on the resistance patterns to three beta-lactams resistant to penicillinase, indicated a different frequency of the resistant strains to these three antibiotics.

The disk diffusion test with oxacillin detected a higher frequency of the resistant strains compared with the methicillin disk diffusion test.

The test using cefoxitin disk diffusion revealed a frequency of 2,51\% resistant strains, that are considered MRSA strains.

Acknowledgement: This research work was carried out with the support of the project „Dezvoltareainfrastructurii de cercetare, educație și servicii în domeniile medicinei veterinare șitehnologiilor inovative pentru RO 05, cod SMISCSNR 2669".

\section{REFERENCES}

1. Bicheru S, Necșulescu M, Cumpănășoiu B, Tîrziu E, Popescu D, Ionescu L, Dumitrescu G, Necșulescu A (2014). PCR for the identification of methicillin resistant staphylococcus aureus (MRSA) strains using primers specific for Sccmec elements, Lucr. Șt. Med. Vet.vol XLVII(2) Timișoara.

2. Boost MV, Ho J, Guardabassi L, O'donoghue MM (2012). High meticillin-resistant Staphylococcus aureus carriage in intensive pig farms in southern China, Veterinary Record 171(6): 156.

3. Codiță I (2008). Identificarea stafilococilor, Tratat de microbiologie clinic sub redacția Buiuc D, Neguț M. Ed. Medicală București 592-606.
4. Codiță I, Buiuc D (2008). Determinarea sensibilității la antibiotice: teste calitative, Tratat de microbiologie clinică, ediţia a II-a, sub redacţia Buiuc D, Neguţ M, Ed. Medicală București 453-482.

5. Gordoncillo MJ, Abdujamilova N, Perri M, Donabedian S, Zervos M, Bartlett P (2012). Detection of methicillinresistant Staphylococcus aureus (MRSA) in backyard pigs and their owners, Michigan, USA, Zoonoses Public Health 59(3):212-216.

6. Gunderson CG, Holleck JL, Chang JJ, Merchant N, Lin S, Gupta S (2016). Diagnostic accuracy of methicillin-resistant Staphylococcus aureus nasal colonization to predict methicillin-resistant S. aureus soft tissue infections, American Journal of Infection Control(16):302-353.

7. Lim SK, Nam HM, Jang GC, Lee HS, Jung SC, Kwak HS (2012). The first detection of methicillin-resistant Staphylococcus aureus ST398 in pigs in Korea, Veterinary Microbiology 155(1):88-92.

8. Pletinckx LJ, Verhegghe M, Crombé F, Dewulf J, DeBleecker Y, Rasschaert G, Butaye P, Goddeeris BM, De Man I (2013). Evidence of possible methicillin-resistant Staphylococcus aureus ST398 spread between pigs and other animals and people residing on the same farm, Preventive Veterinary Medicine 109(3-4):293-303.

9. Vanderhaeghen W, Van De Velde E, Crombé F, Polis I, Hermans K, Haesebrouck F,Butaye P (2012). Screening for methicillin-resistant staphylococci in dogs admitted to a veterinary teaching hospital, Research in Veterinary Science 93(1):133-136.

10. Vanderhaeghen W, Vandendriessche S, Crombé F, Nemeghaire S, Dispas M, Denis O, Hermans K, Haesebrouck F, Butaye P (2013). Characterization of methicillinresistant non-Staphylococcus aureus staphylococci carriage isolates from different bovine populations, The Journal of Antimicrobial Chemotherapy 68(2):300-307. 